\title{
Preliminary results of ground-motion characteristics
}

\author{
Francesca Bozzoni ${ }^{1,{ }^{\star}}$, Carlo G. Lai ${ }^{1,2}$, Laura Scandella ${ }^{1}$ \\ ${ }^{1}$ European Centre for Training and Research in Earthquake Engineering (EUCENTRE), Pavia, Italy \\ ${ }^{2}$ Università di Pavia, Dipartimento di Ingegneria Civile ed Architettura, Pavia, Italy
}

\author{
Article history \\ Received July 22, 2012; accepted August 20, 2012. \\ Subject classification: \\ Seismology - Ground motion.
}

\section{Introduction}

On May 20, 2012, a $\mathrm{M}_{\mathrm{W}} 5.9$ earthquake struck the Emilia-Romagna Region in northern Italy (Figure 1a), causing severe shaking throughout a relatively large portion of the Po Plain territory. The epicenter of this May 20, 2012, event has the coordinates $44.89^{\circ}$ (latitude) and $11.23^{\circ}$ (longitude). The depth of the hypocenter has been estimated at $6.3 \mathrm{~km}$. The focal mechanism is of the thrust type.

On May 29, 2012, a $\mathrm{M}_{\mathrm{W}} 5.65$ shock hit the region, causing further damage and fatalities. Figure $1 \mathrm{~b}$ shows the events with magnitudes $>4.5$ (Figure 1b, red dots) of this sequence of MayJune 2012 (data retrieved from http:/ / iside.rm.ingv.it/iside / standard/index.jsp). Figure $1 \mathrm{~b}$ also shows the most important earthquakes that have occurred in the northern parts of the Emilia-Romagna Region over the latest 500 years (Figure 1b, green dots). The data were retrieved from the Italian earthquake catalogue CPTI11 (http: / / emidius.mi.ingv.it/CPTI11/) of the Istituto Nazionale di Geofisica e Vulcanologia (INGV; National Institute of Geophysics and Volcanology). The Ferrara territory was hit by a M 5.5 earthquake on November 17, 1570. On July 11, 1987, a M 5.4 event struck the Po Plain area close to Bologna and Ferrara. Other historical earthquakes with magnitudes up to 6 have occurred in the southern part of the Emilia-Romagna Region, close to the Apennine chain. The area struck by the Emilia May-June 2012 sequence is located south of the Po Plain, in the foreland basin of two mountain belts constituted by the Alps and the northern Apennine chains. Under thick clastic sedimentary fills along the northern and southern margins of the Po Plain, complex systems of thrust sheets and tectonic structures are buried. Due to the fast sedimentation rates and comparatively low tectonic rates, the thrusts are generally buried and there is little surface evidence of their activity [Toscani et al. 2009].

\section{Shake maps}

Shake maps provide a first estimate of the spatial distribution of ground motion. Data from the recording stations of the Italian Strong Motion Network (RAN) and the Strong
Motion Network of Northern Italy (RAIS) have been used for this purpose. The maximum peak ground acceleration (PGA) was recorded at the station of Mirandola (MRN) (located at ca. $13.4 \mathrm{~km}$ from the epicenter), and it is associated to the vertical component, which reached $0.31 \mathrm{~g}$. Figure 2 shows a shake map computed by interpolating the recorded PGA at the RAN stations using the inverse distance weighted algorithm. The stations are located at sites classified as category $\mathrm{C}$ according to the soil classification system prescribed by the Italian Building Code [NTC 2008] which is similar to that of Eurocode 8 Part 1 [EN 1998-1, 2005].

From Figure 2 it is worth noting that the pattern of the contour lines of the PGA is nonsymmetric with respect to the epicenter. This is due to the small number of stations used to perform the interpolation (the station closest to the epicenter is MRN). The focal mechanism might have also had a role in this asymmetry. It is important to note that the distance between the epicenter and the closest station influences the quality of the PGA estimation in the area.

Ground-motion parameters from the recordings provided by the RAN and RAIS seismic networks were compared with the estimates of two recent ground-motion prediction equations (GMPEs); namely those of Cauzzi and Faccioli [2008] and Bindi et al. [2011]. The preliminarily predictions were made for Soil Category C. Figure 3 and Figure 4 show the horizontal PGA predicted by the selected GMPEs. Particularly in the case of the Cauzzi and Faccioli [2008] GMPE, the predicted values are very high in the epicentral area. The predicted PGA is in good agreement with the recordings from the RAN and RAIS stations.

\section{Recordings and response spectra at Mirandola station}

The closest station to the epicenter of the May 20, 2012, event is MRN, which belongs to the RAN network (managed by the Italian Department of Civil Protection). The epicentral distance of this station is ca. $13.4 \mathrm{~km}$. Time histories recorded at the MRN station have been analyzed to obtain acceleration, velocity, and displacement response spectra. 
The recorded signals, which are the horizontal South-North $(\mathrm{SN})$, East-West (EW) and vertical (UP) components, were processed for standard baseline correction, band-pass filtered from $0.05 \mathrm{~Hz}$ to $50 \mathrm{~Hz}$, tapered, and linearly de-trended in velocity. Table 1 shows the peak ground-motion parameters, namely the PGA, the peak ground velocity (PGV), and the peak ground displacement (PGD), for each component recorded at the MRN station.

The acceleration response spectra computed using the recordings of the MRN station are shown in Figure 5a (horizontal components) and in Figure 5b (vertical component). The vertical component of the spectral acceleration has the peak at a lower period $(0.06 \mathrm{~s})$, compared with the horizontal components (SN: $0.17 \mathrm{~s}$; EW: $0.31 \mathrm{~s})$. Furthermore, the

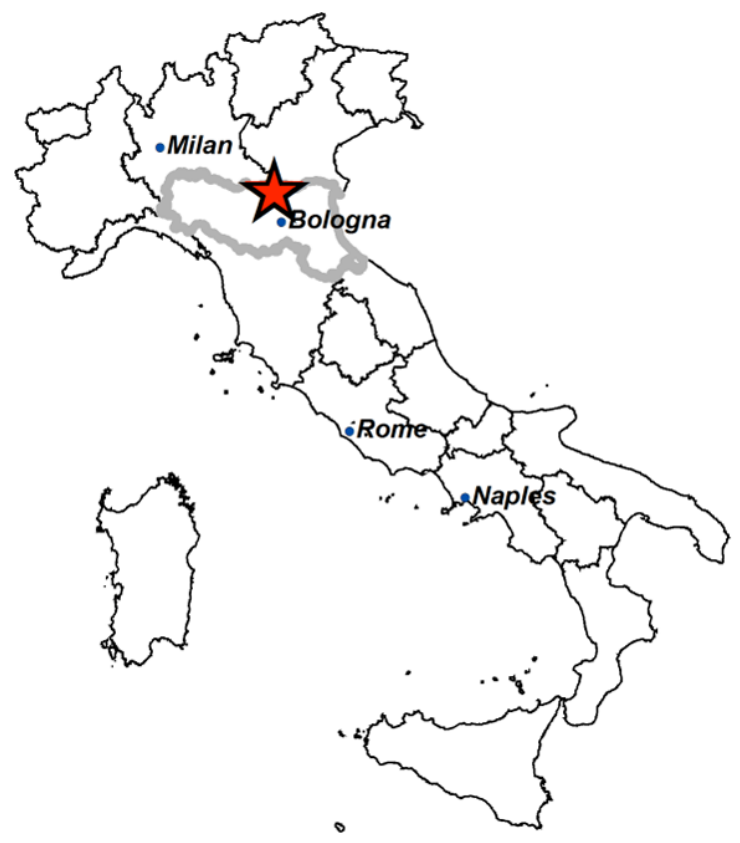

\begin{tabular}{cccc}
\hline & PGA (g) & PGV $(\mathbf{m} / \mathbf{s})$ & PGD (m) \\
\hline SN & 0.264 & 0.463 & 0.105 \\
EW & 0.262 & 0.300 & 0.081 \\
UP & 0.310 & 0.059 & 0.018 \\
\hline
\end{tabular}

Table 1. Peak ground-motion parameters for each component recorded at the MRN station. PGA, peak ground acceleration; PGV, peak ground velocity; PGD, peak ground displacement).

peak values of the spectral acceleration for the vertical component are concentrated in a narrow band of periods from 0.02 to $0.12 \mathrm{~s}$, while the peaks of the spectral acceleration for the horizontal components occur at a band with higher periods of up to $0.5 \mathrm{~s}(\mathrm{EW})$ and $1.3 \mathrm{~s}(\mathrm{SN})$.

The acceleration response spectra computed using the recordings from the MRN station were also compared with the predictions of the GMPE developed by Bindi et al. [2011] for the horizontal component and for Soil Category C (Figure 6a). The mean predictions of the GMPE are satisfactory for periods $<0.17 \mathrm{~s}$, whereas for larger periods, the GMPE strongly underestimates the severity of the record. The displacement response spectra computed using the recordings from the MRN station were compared with the spectra predicted by the GMPE developed by Cauzzi and Faccioli [2008] for the horizontal component and for Soil Category C (Figure 6b). In this case, the GMPE severely underestimates the spectra calculated from the records for all of the structural periods.

The records from the MRN station were used to plot the particle orbit (hodogram) described by the waveform. The a) hodogram was plotted in the plane of Rayleigh wave propa-

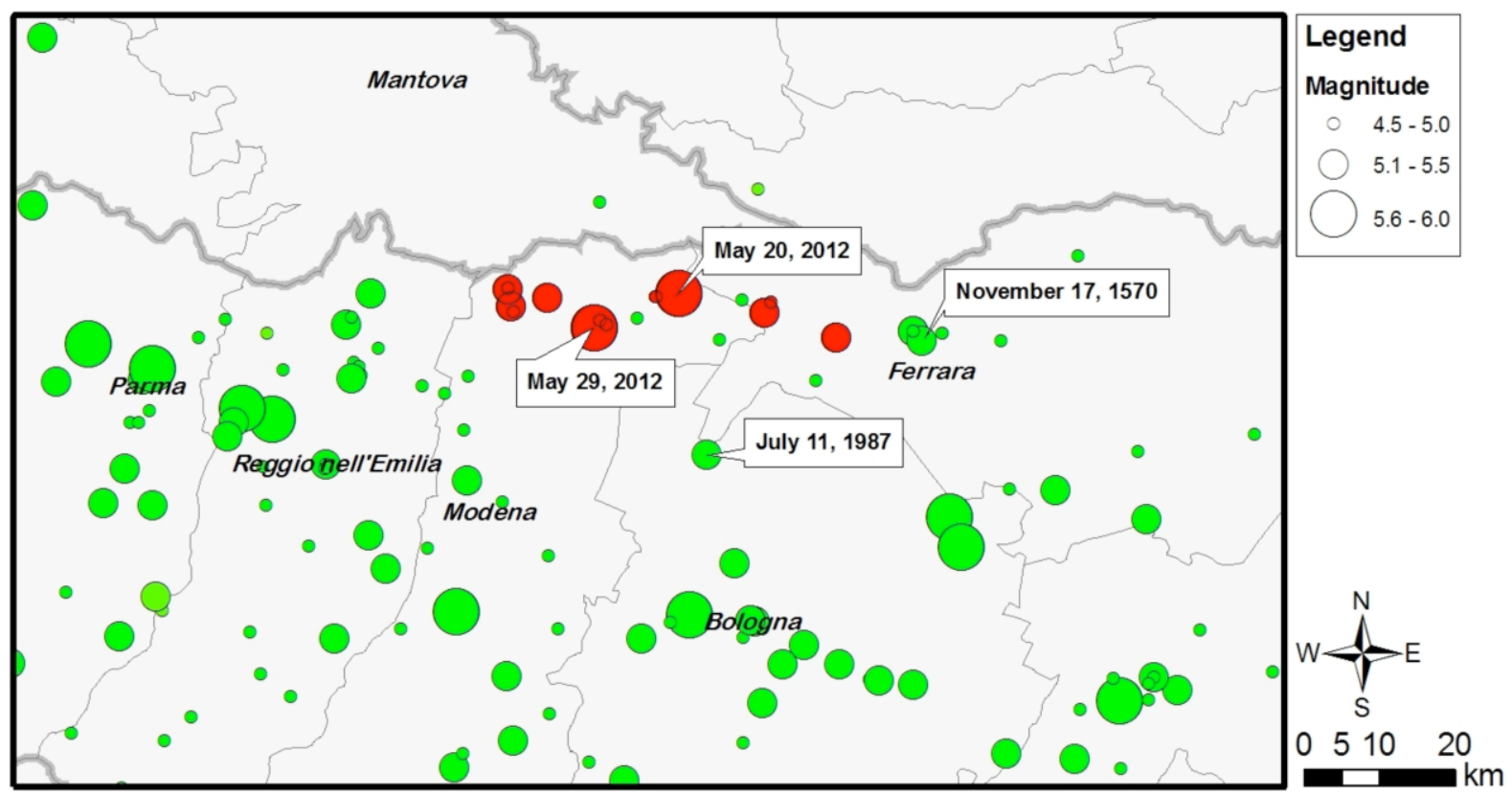

b)

Figure 1. (a) Location in the Emilia-Romagna Region of the May 20, 2012, earthquake. (b) Distribution of the major historical earthquakes as green dots (http:/ / emidius.mi.ingv.it/CPTI11/), and of the M >4.5 events of the 2012 sequence as red dots (http:/iside.rm.ingv.it/). 


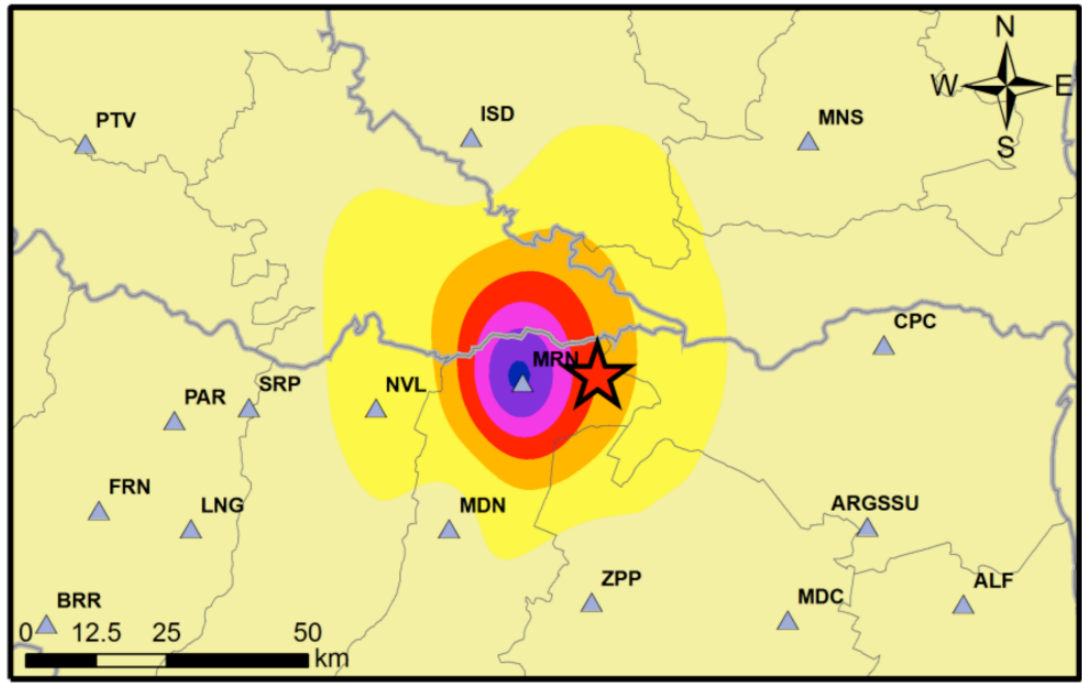

\section{Legend}

$\triangle$ RAN Stations

\section{Recorded PGA (g) - RAN}

$\square 0.000-0.050$

$0.051-0.100$

$0.101-0.150$

$0.151-0.200$

$0.201-0.250$

$0.251-0.300$

$0.301-0.310$

Modena Earthquake, May 20, 2012 Ml=5.9

Figure 2. Shake map obtained from the interpolation of the PGA recorded by the RAN seismic network. Ground conditions for the seismic stations are similar, and they are approximately associated to the Soil Category C, according to the ground classification system of the Italian Building Code [NTC 2008], which is similar to that of Eurocode 8 Part 1 [EN 1998-1, 2005].

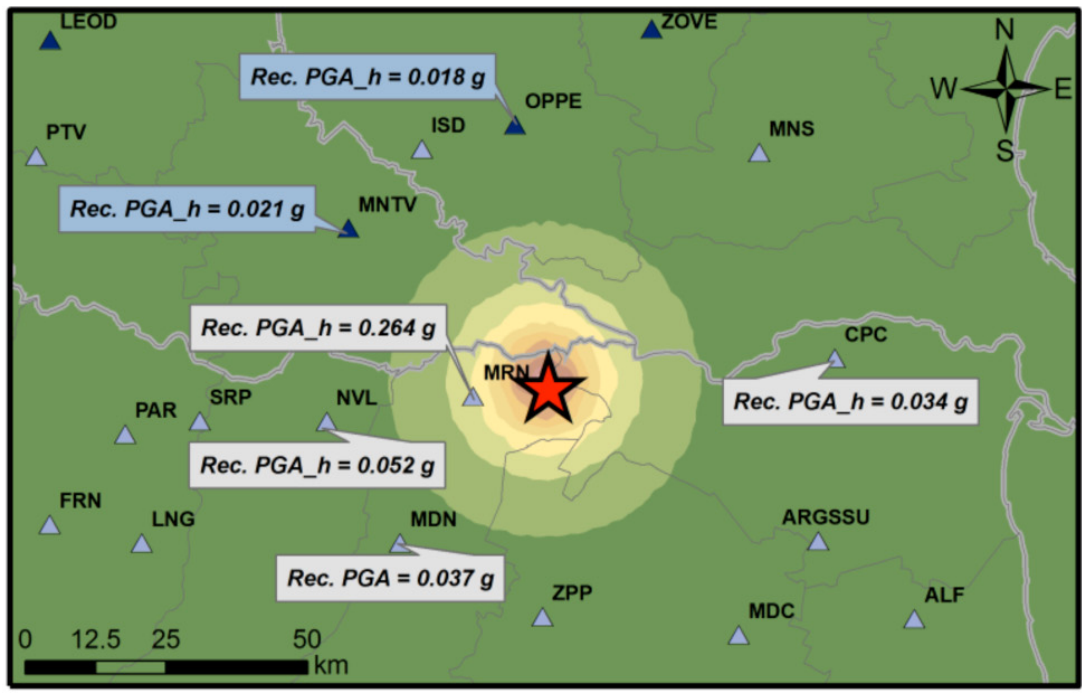

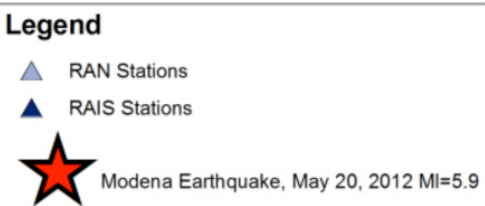

Predicted PGA_h (g) - CF08 Soil C

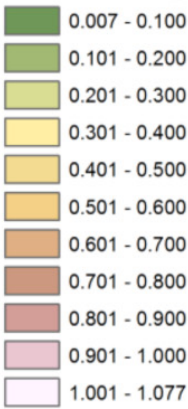

Figure 3. Median values of the PGA (horizontal component) predicted by the GMPE of Cauzzi and Faccioli [2008] for Soil Category C, plotted on top of the recorded values of the PGA at selected stations of the RAN and RAIS strong-motion networks.

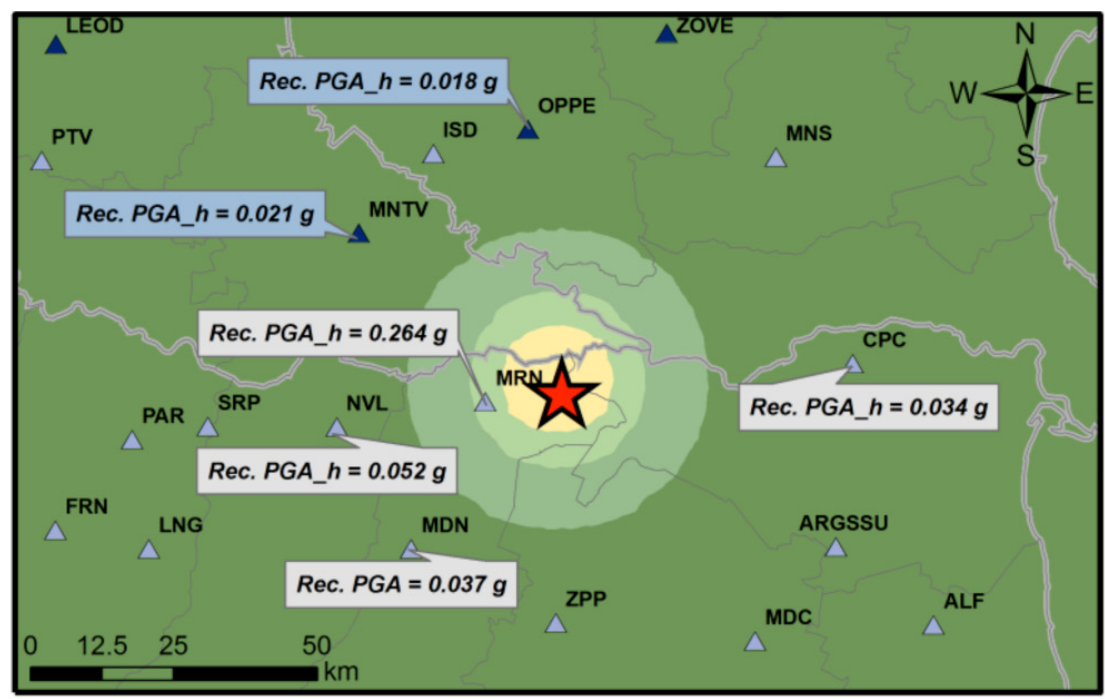

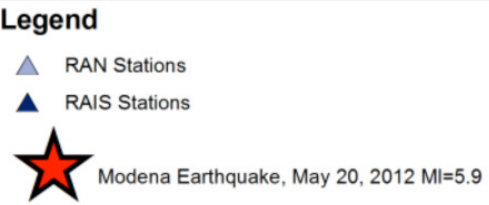

Predicted PGA_h (g) - Bindi11 Soil C

$0.006-0.100$

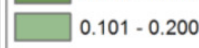

$\square 0.201-0.300$

$0.301-0.400$

$0.401-0.403$

Figure 4. Median values of the PGA (horizontal component) predicted by the GMPE of Bindi et al. [2011] for Soil Category C, plotted on top of the recorded values of the PGA at selected stations of the RAN and RAIS strong-motion networks. 

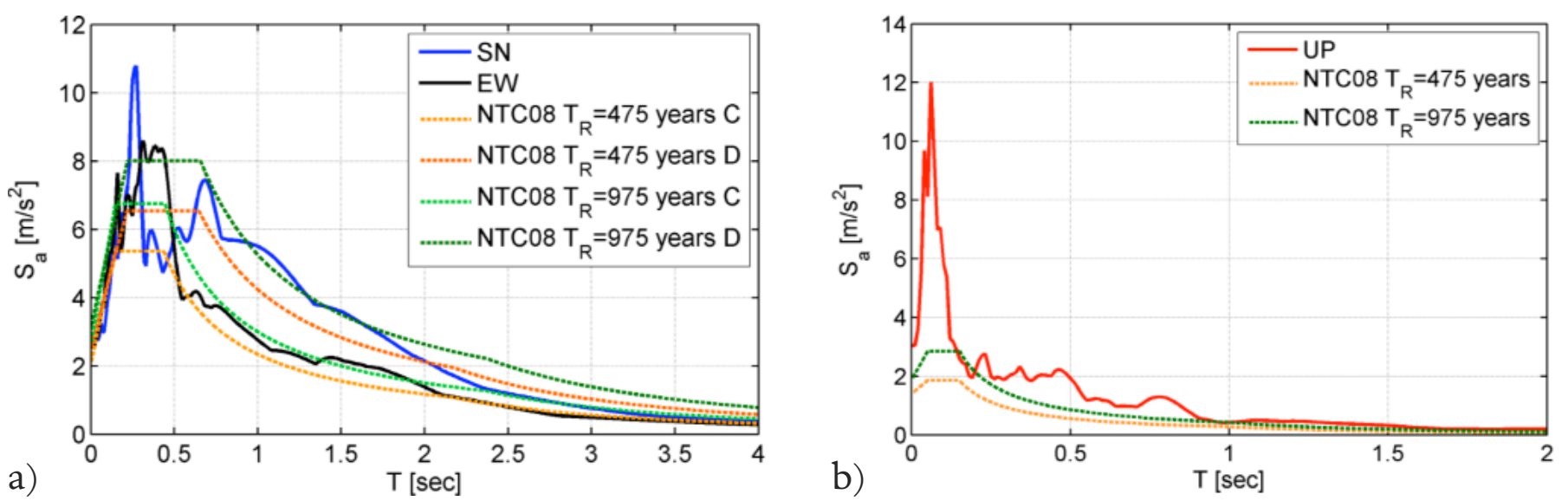

Figure 5. Mirandola station recordings. (a) Comparison of the horizontal (SN, EW) acceleration response spectra from the recordings with the spectra from the Italian Building Code [NTC 2008], computed for Soil Categories C and D for 475-year and 975-year return periods. (b) Comparison of the vertical (UP) acceleration response spectra from the recordings with the spectra from the Italian Building Code [NTC 2008] computed for 475-year and 975-year return periods.
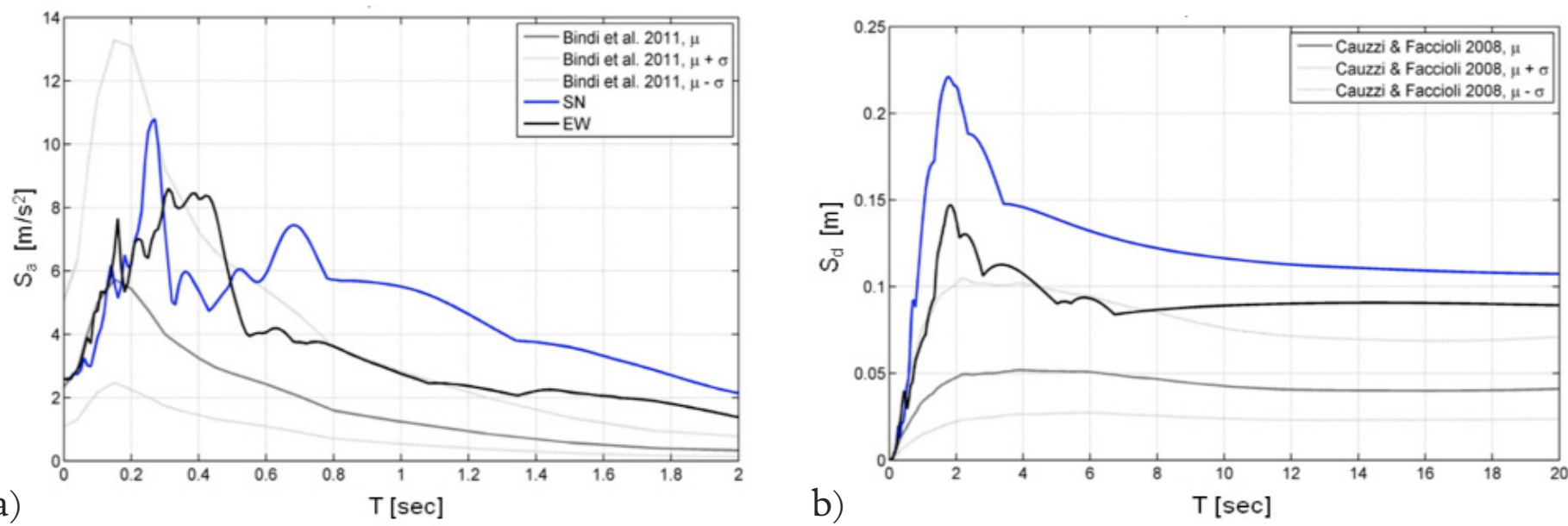

Figure 6. Mirandola station recordings. (a) Comparison of the horizontal (SN, blue line; EW, black line) acceleration response spectra from the recordings with the Bindi et al. [2011] GMPE for ground category C. (b) Comparison of the horizontal (SN, blue line, EW, black line) displacement response spectra from the recordings with the Cauzzi and Faccioli [2008] GMPE for Soil Category C.

gation. Inspection of the MRN recordings shows that the backscattered P-wave and SV-wave are not well time-separated from the Rayleigh wave arrival, given that the MRN station is very close to the epicenter. Figure 7 shows the radial and vertical displacement traces obtained through filtering the signals with band-passes between $0.1 \mathrm{~Hz}$ and $0.5 \mathrm{~Hz}$ (from $2 \mathrm{~s}$ to $10 \mathrm{~s}$ ). The motion is characteristically retrograde elliptical.

\section{Preliminary ground-response analysis at Mirandola}

The availability of results from geotechnical field tests performed at a few sites in the Municipality of Mirandola prior to the earthquake of May 2012 have allowed preliminary assessment of the ground response closest to the MRN station. The corresponding data were retrieved from the WebGIS portal of the Emilia-Romagna Region (https: / / territorio.regione. emilia-romagna.it/cartografia/ cartografia-sgss). Data from five seismic tests using multichannel analyses of surface waves that were performed during a 2011 geophysical campaign were used to construct a geotechnical model of the subsoil at Mirandola, which was successively adopted to perform

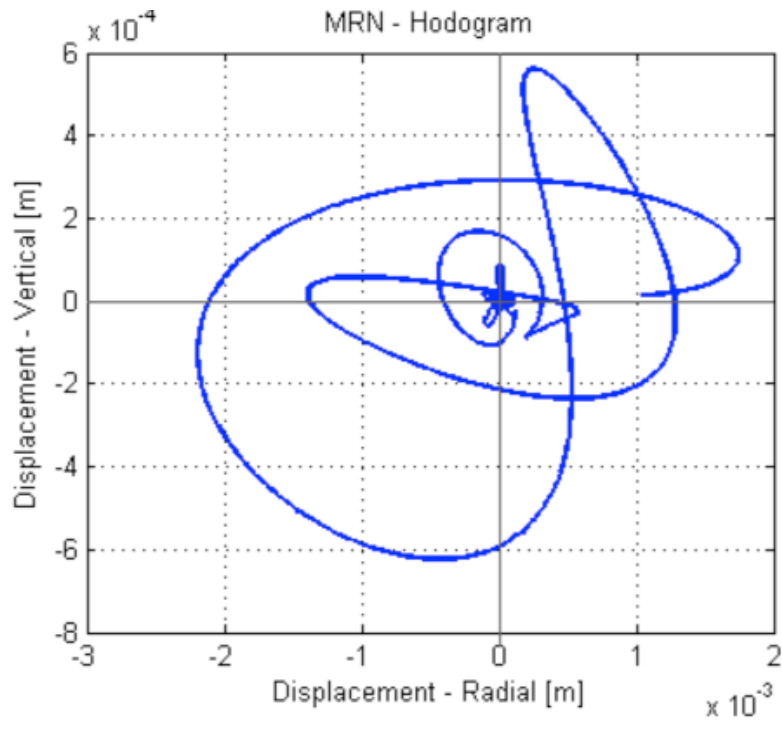

Figure 7. Hodogram from the Mirandola station recordings: the radial and vertical displacement traces.

ground-response analyses. Geological information about the soil deposits at the MRN site was retrieved at the portal 


\begin{tabular}{|c|c|c|c|c|c|c|c|}
\hline Layer & Soil type & $\begin{array}{l}\text { Thickness } \\
(\mathbf{m})\end{array}$ & $\begin{array}{c}\text { Uncertainty } \\
(\%)\end{array}$ & $\begin{array}{c}\mathbf{V}_{\mathbf{S}} \\
(\mathbf{m} / \mathbf{s})\end{array}$ & $\begin{array}{c}\text { Uncertainty } \\
(\%)\end{array}$ & $\begin{array}{c}\rho \\
\left(\mathbf{k N} / \mathbf{m}^{3}\right)\end{array}$ & $\begin{array}{c}\text { Uncertainty } \\
(\%)\end{array}$ \\
\hline 1 & Sand & 6.6 & 67 & 150 & 12 & 18 & 6 \\
\hline 2 & Sand & 7.8 & 68 & 221 & 33 & 18 & 6 \\
\hline 3 & Sand & 9.7 & 67 & 266 & 19 & 18 & 6 \\
\hline 4 & Sand & 7.1 & 44 & 312 & 18 & 18 & 6 \\
\hline 5 & Sandy clay and clayey sand & 10.0 & 50 & 379 & 20 & 19 & 6 \\
\hline 6 & Sandy clay and clayey sand & 15.0 & 50 & 480 & 25 & 19 & 6 \\
\hline 7 & Sandy clay and clayey sand & 15.0 & 50 & 600 & 20 & 19 & 6 \\
\hline 8 & Sandy clay and clayey sand & 35.0 & 40 & 700 & 20 & 19 & 6 \\
\hline- & Bedrock & - & - & 800 & 20 & 20 & 6 \\
\hline
\end{tabular}

Table 2. Means of the geotechnical parameters and the corresponding uncertainties assumed for the adopted subsoil model.

a)

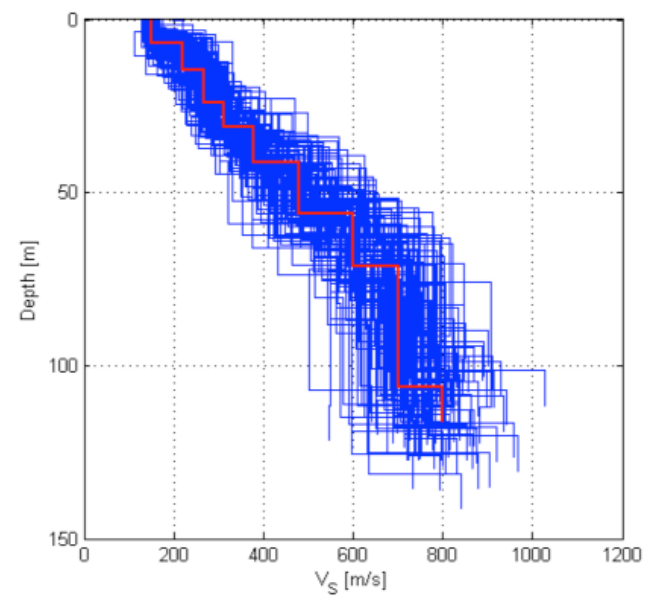

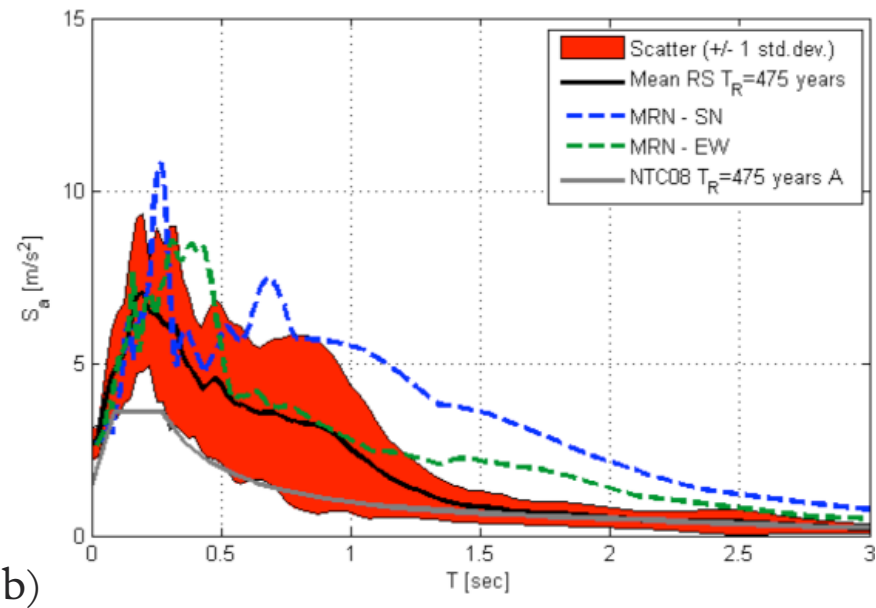

Figure 8. Stochastic ground-response analyses at Mirandola. (a) One hundred random $V_{S}$ profiles generated using the Latin Hypercube sampling technique. Red line, mean profile. (b) Mean acceleration response spectrum with the associated scatter computed using the $V_{S}$ profiles of (a). The seismic input comprised seven actual records compatible with the Italian code-based spectrum that refers to a 475 -year return period. The computed spectra are compared to the SN and EW spectra calculated from the MRN station recordings. The spectrum code [NTC 2008] for Soil Category A is also shown.

http:/ itaca.mi.ingvit/ItacaNet/. Table 2 gives the mean values of the geotechnical parameters and the corresponding uncertainties assumed for the adopted subsoil model.

One-dimensional (1D) linear-equivalent, fully stochastic site-response analysis was performed for the MRN station using the methodology described in Rota et al. [2011], which takes into account the uncertainties associated with the geotechnical model parameters. The stochastic analysis was carried out using Monte Carlo simulations associated with the Latin Hypercube sampling technique. Randomly generated geotechnical parameters varying within correctly defined probability distributions were assumed to calculate the seismic response of 100 deterministic realizations of the geotechnical model. The uncertainty adopted for the values of $\mathrm{V}_{S}$ is shown in Figure 8a where the red line denotes the mean of $100 \mathrm{~V}_{\mathrm{S}}$ profiles with layers of varying thicknesses. For the definition of the depth of the bedrock and of its stiffness, the data available at the website of the Emilia-Romagna Region were used (http:/ / ambiente.regione.emilia-romagna.it).
The variability of the seismic input was taken into account by considering an appropriate set of seismo- and spectrum-compatible natural records. Specifically, a set of seven accelerograms that were recorded from actual earthquakes were downloaded for the area under investigation, from the portal: http://www.eucentre.it/seismhome.html. The selected accelerograms have magnitudes that range from 6 to 6.87 , and epicentral distances that vary from $11 \mathrm{~km}$ to 102 $\mathrm{km}$. Their scaling factors range from 0.36 to 2.61 , with a mean of 1.60. The signals were recorded under outcropping rock conditions, and they are spectrum-compatible, on average, to the Italian code-based spectrum [NTC 2008] that refers to the 475 -year return period. Indeed, although it is still premature to make definitive conclusions, a lot of seismological evidence appears to suggest that the May 20, 2012, earthquake might correspond to this return period.

Figure $8 \mathrm{~b}$ shows the mean acceleration response spectrum \pm one standard deviation, which was calculated using the linear-equivalent, fully stochastic, 1D ground response 
analyses described above. This spectrum is compared to the response spectra calculated from the $\mathrm{SN}$, EW recordings of the MRN station for the May 20, 2012, event. Figure $8 \mathrm{~b}$ also shows the code-based spectrum for Soil Category A [NTC 2008]. The mean PGA computed from ground-response analysis turned out to be $0.269 \mathrm{~g}$, which is in excellent agreement with the recorded PGA (see Table 1). However the peaks of the MRN spectra are underestimated by the mean spectrum. Better agreement appears to be obtained by considering the mean spectrum plus one standard deviation, especially in the case of the EW component, although only for periods up to ca. $1 \mathrm{~s}$. For periods $>1 \mathrm{~s}$, the spectral accelerations of the MRN recordings, and in particular those of the SN component, exceed those of the computed spectra.

Possible explanations for this difference might be nearfault effects, as the MRN station lies only $13 \mathrm{~km}$ away from the epicenter, and also that the May 20, 2012, earthquake was a shallow event (with a focal depth of about $6.3 \mathrm{~km}$ ). Possible explanations for such differences at large periods might also be non-linear effects (liquefaction), which might have occurred at the recording station. Further investigation is however needed to substantiate these preliminary statements. Ground-response analyses focused on the propagation of $S$-waves only, as they are the most relevant for engineering applications. Future studies can investigate the role, if any, of ground amplification in the propagation of P-waves.

\section{Concluding remarks}

The preliminary results of our ground-motion calculations from the recordings of the May 20, 2012, M 5.9 Emilia earthquake have been presented here. The response spectra computed from the accelerograms recorded at the MRN station, as the closest to the epicenter, have been compared with the spectra predicted by two recent GMPEs and the Italian Building Code [NTC 2008]. A first attempt evaluation of the amplification effects at Mirandola has been carried out through linear-equivalent, fully stochastic ground-response analyses based on the results from geotechnical field tests performed close to the MRN station and using a set of seven actual records that are compatible to the Italian code-based spectrum that refers to a 475 -year return period. Investigations are currently underway to determine whether linearequivalent analyses are admissible in Mirandola, in light of possible strongly nonlinear effects (liquefaction) that might have occurred at the recording station.

The results of the analyses show that the mean computed PGA is in excellent agreement with the recorded PGA at the MRN station (SN, EW). However, the peaks of the MRN spectra are underestimated by the mean spectrum. Better agreement appears to be obtained by considering the mean spectrum plus one standard deviation, although only for periods up to ca. $1 \mathrm{~s}$. For periods $>1 \mathrm{~s}$, the spectral accelerations of the MRN recordings, and especially of the SN component, exceed those of the computed spectra. Possible explanations for this difference include near-fault effects (the MRN station lies only about $13 \mathrm{~km}$ away from the epicenter) and that the May 20,2012, earthquake was a shallow event (focal depth of $6.3 \mathrm{~km}$ ).

Acknowledgements. The authors would like to acknowledge the support of the Department of Civil Protection of the Italian Government, and that of the Administration of the Emilia-Romagna Region. A word of gratitude goes to Dr. Maria-Daphne Mangriotis, for her valuable suggestions.

\section{References}

Bindi, D., F. Pacor, L. Luzi, R. Puglia, M. Massa, G. Ameri and R. Paolucci (2011). Ground motion prediction equations derived from the Italian strong motion database, B. Earthq. Eng., 9, 1899-1920.

Cauzzi, C., and E. Faccioli (2008). Broadband (0.05 to 20 s) prediction of displacement response spectra based on worldwide digital records, J. Seismol., 3; doi:10.1007/s10 950-008-9098-y.

EN 1998-1 (2005). Eurocode 8 - Design of Structures for Earthquake Resistance - Part 1: General rules, seismic actions and rules for buildings, EN 1998-1, CEN, Brussels.

NTC (2008). Norme tecniche per le Costruzioni, D.M. 14.1.2008 (Italian Building Code).

Rota, M., C.G. Lai and C.L. Strobbia (2011). Stochastic 1D site-response analysis at a site in central Italy, Soil Dyn. Earthq. Eng., 31, 626-639.

Toscani, G., P. Burrato, D. Di Bucci, S. Seno and G. Valensise (2009). Plio-Quaternary tectonic evolution of the northern Apennines thrust fronts (Bologna-Ferrara section, Italy): Seismotectonic implications, B. Soc. Geol. Ital., $128,605-613$.

\footnotetext{
${ }^{\star}$ Corresponding author: Francesca Bozzoni, European Centre for Training and Research in Earthquake Engineering (EUCENTRE), Pavia, Italy; email: francesca.bozzoni@eucentre.it.

C 2012 by the Istituto Nazionale di Geofisica e Vulcanologia. All rights reserved.
} 